\title{
HAVA YOLU TAŞIMACILIĞI SEKTÖRÜNDE İFLAS RİSKİ - YAPAY SİNİR AĞLARI İLE AİRSCORE TAHMİNİ
}

\author{
BANKRUPTCY RISK OF AIR TRANSPORTATION SECTOR -AIRSCORE \\ FORECASTING WITH NEURAL NETWORKS
}

\author{
Burcu SAKIZ ${ }^{* *}$ \\ Gülü̈mser ÜNKAYA ${ }^{* * *}$
}

\section{Öz}

Son yıllarda dünyada havacılık sektörüne olan talep, kargo ve yolcu taşımacılığının önemini arttırmış, küresel çapta yoğun bir rekabeti de beraberinde getirmiştir. Riskleri ve finansal performansı düzenli olarak değerlendirmek, havayollları gibi dışarıdan gelen etkilere duyarlı, talebi döngüsel, sabit maliyetleri yüksek bir endüstride sürdürülebilir başarıyı yakalayabilmek adına elzemdir. Amerika’da 1978 yılında havayollarının deragülasyonu ile başlayan değişim ve rekabet, sektörde iflasları da beraberinde getirmiştir. Özellikle 21. yüzyılın ilk yıllarında havacılık sektörünü etkileyen önemli gelişmeler yaşanmıştır. Bir üçüncü nesil finansal kriz modeli olan 2008 krizi de dahil olmak üzere havac1lık endüstrisini küresel çapta etkileyen önemli dört olay, 11 Eylül 2001 terör saldırısı, 2003 yılındaki SARS hastalığı salgını ve 2010 yılındaki volkanik kül patlamasıdır. Bu araştırma, bahsi geçen olayların Türk Hava Yolları Anonim Ortaklığı için iflas riskini, diğer iflas tahmin modelleri arasında havacılık sektörüne özgü geliştirilmiş Airscore modeliyle ortaya koyma ve yapay sinir ağları teknikleri ile tahminleme amacını taşımaktadır. Ortaklığın, Airscore iflas tahmin modeline göre incelenen 2002 ile 2016 yılları arasındaki dönemin sağlıklı alan olarak nitelendirilen bölgede olduğu tespit edilmiştir. Bu çalışma kapsamında tüm bu yapılanlara ek olarak yapay zekâ algoritmaları yardımıyla gerçekleştirilen

* Makalenin Gönderim Tarihi: 08.04.2018 Kabul Tarihi: 09.07.2018

** İstanbul Aydın Üniversitesi, Sosyal Bilimler Enstitüsü, İşletme Anabilim Dalı, Doktora Öğrencisi, ORCID ID: 0000-0001-8026-4775

*** İstanbul Aydın Üniversitesi, İktisadi ve İdari Bilimler Fakültesi, Muhasebe ve Finans Yönetini Bölümü, Prof. Dr., ORCID ID: 0000-0003-2453-2223 
analizlerde, önceki bulgulara benzer şekilde takip eden üç dönem için Türk Hava Yolları A.O iflas riski açısından sağlıklı alanda olacağı tahmin edilmiştir.

Anahtar Kelimeler: Hava Yolu Taşımacılığı, İflas Tahmin Modelleri, Airscore, Yapay Zeka

JEL Sınıflaması: G32,G33,C45

\section{Abstract}

In the recent years, increasing demand for air transportation in the world has increased the importance of passenger and cargo transportation services and brought intensive competition in national and international markets globally. Evaluating the financial performance and risks of enterprises regularly under destructive competition and taking necessary actions while performing business tasks by standing in a constantly changing, developing and growing market becomes mandatory in order to achieve sustainable success. The airline industry sector is structurally challenged by its very nature, facing high fixed costs, cyclical demand, intense competition, and vulnerability to external shocks like terrorist attacks, disasters, global financial crisis after economic deregulation in 1978. Especially the deregulation in 1978 of the United Stated of America's airline industry led to a paradigm shift in the market as routes opened up, forcing the legacy carriers in the industry into a highly competitive, lowfare environment. As competition increases, it is crucial for airline firms to know, evaluate and analyze which core business areas are essential to prevent bankruptcy and to success. It appears that a number of indicators specific to airline firms have been used along with the widely used financial ratios to analyze the financial situation of companies operating in the airline sector. Airline finance managers, analysts and interested business owners can take better decisions and make correct planning and budgets via regularly calculating important financial ratios and indicators, comparing them for past periods and years, risk analyzing, creating appropriate reports, making estimations for the future periods, developing simulations for future scenarios when necessary and performing benchmarks. Since the structure of each industry and its business, its internal dynamics and its environment are different; successful risk applications and models used and developed for other sectors may not be suitable for airline firms. For this reason, airline operators should establish their own models according to airline business dynamics. Airlines often seem to avoid taking too much risk, especially focusing on decreasing financial risks and trying to limit exposure to the risks associated with business activities. The aim of this study is to estimate and assess the airline firms' bankruptcy situation by applying feasible models, by providing information that will assist in the analysis and interpretation of financial statements of the financiers and related businesses on a growing airline sector. Also the development of the airline industry in the world and Turkey is discussed and information about the models used in analyzing the financial situation of airline companies is given and various calculations is made. Airscore model, which is a model specific to the aviation industry, is chosen from the bankruptcy prediction models and evaluated using the Turkish Airlines financial values which is open to public, and forecasted by backpropagated artificial neural network algorithms. In the application part, it is aimed to reveal and predict the bankruptcy risk on the Turkish Airlines for four important events that affect the aviation industry on a global basis since 2000 by using Airscore model which is a unique model developed only for airline sector. These four disruptive events include the terrorist attack which took place on the September 11, 2001 in New York World Trade Center; the SARS outbreak, which started 
in 2003 in far east; the global financial crisis in 2008 which was the worst economic disaster since the Great Depression; and the volcanic ash eruption in Iceland in 2010 resulted to cancellation of a lot of flights, re-routing of aircrafts and temporary closing of partial European airspace. In the first part of the study, air transportation definitions and concepts is discussed and basic information is given about the subject. In the second part, bankruptcy measurement methods, sector specific financial risk assessment models and risk management methods used in the model are explained. Moreover, data rates and indicators specific to airlines have been described and previous work on the subject has been addressed. In the application section, predictions are made with Airscore bankruptcy prediction model calculations and artificial intelligence algorithms, and the findings obtained in the result section were evaluated using Turkish Airlines financial and operations data between yeras 2002 and 2016. It was determined that the period between 2002 and 2016, which was analyzed according to the Airscore bankruptcy prediction model, was in the area considered as healthy. Also in this study, with the help of artificial intelligence algorithms it is predicted that for the next three periods, Turkish Airlines will be in healthy area in terms of risk of bankruptcy by analyzes similar to previous periods in our findings.

Keywords: Airline Transportation, Bankruptcy Forecasting Models, Airscore, Artificial Intelligence JEL Classification: G32, G33, C45

\section{GíRiş}

Dünyada son yıllarda giderek daha çok talep gören havayolu taşımacıllı̆̆, sektörde hizmet veren yolcu ve kargo taşıma işletmelerinin önemini küresel çapta arttırmıştır. Ulusal ve uluslararası pazarda yoğun bir rekabet altında faaliyet gösteren havacılık sektörü işletmelerinin finansal durumlarını analiz edip yorulmayabilmek için tüm sektörlerde değerlendirme yaparken yaygın olarak kullanılan finansal oranlar ile birlikte, bu işletmelere özgü bir takım göstergelerin de kullanıldığı görülmektedir. Bu oranların ve göstergelerin hesaplanıp geçmiş dönemler ve yıllar için karşılaştırılmalar yapılarak risklerin değerlendirilmesi, uygun raporların oluşturulması, tahminlerin yapılması; havayolu finans yöneticilerine, analistlere ve ilgililere işletmenin durumunu daha iyi değerlendirme ve daha sağlıklı planlama yaparak doğru kararlar alma olanağı verecektir.

Üreticiler ve tüketiciler başta olmak üzere bütün ekonomik aktörlerin, krizlerin sebep olacağı etkileri minimum seviyeye indirebilmek amacıyla, kriz olasılığına karşı gerekli önlemleri zamanında almaları gerekmektedir. Bunu mümkün kılan ise, kriz öncesinde, kriz olasılığının habercisi olan sinyalleri alabilmektedir ve son yıllarla iktisatçılar ile işletmecilerin üzerinde çalıştıkları konulardan biri de ekonomik krizlerin önceden tahmin edilmesi olmuştur (Dursun, Birdal, 2011). Yalnız her sektörün ve işletmenin yapısı, iç dinamikleri, çevresi farklı olduğundan diğer sektörlerdeki başarılı olan risk uygulamaları ve modelleri, havayolu işletmeleri için elverişli olmayabilir. Bu sebeple havayolu işletmeleri kendilerine 
özgü modeller kurmalıdır. Havayollarının genellikle gereğinden fazla risk üstlenmekten kaçınmak, özellikle finansal riskler üzerinde durmak ve maruz kalınan riskleri iş aktiviteleri ile ilişkilendirilen risklerle sınırlandırmaya çalışmak üzerine çalıştıkları görülmektedir.

$\mathrm{Bu}$ çalışmada hedeflenen, havayolu sektöründeki finans yöneticilerine ve ilgililere işletmelerin finansal durumunun analiz ve yorum kısmında yardımcı olacak bilgileri vererek işletmenin iflas durumu hakkında uygulanabilir modellere göre tahminleme ve değerlendirme yapmalarını sağlamaktır. Araştırma kapsamında gerek teorik bilgilere gerekse uygulamaya yönelik bilgilere yer verilerek havayolu sektörünün gelişimi ele alınacak, okuyucunun havayolu işletmelerinin finansal durumlarını analiz ederken kullanılan modeller hakkında bilgi sahibi olması sağlanacaktır.

Uygulama kısmında, havacılık endüstrisini küresel çapta etkileyen önemli 4 olayın Türk Hava Yolları Anonim Ortaklı̆̆ı (THY A.O.) üzerindeki iflas riskini, iflas tahmin modellerinden Airscore modelini kullanarak ortaya koyma ve tahminleme yapılması hedeflenmiştir. Araştırma kapsamında ele alınan önemli olayların ilki 11 Eylül 2001 yılında yaşanan terör saldırısı, ikincisi uzakdoğuda 2003 yılında baş gösteren SARS hastalığı salgını, üçüncüsü 2008 yllında yaşanan finansal kriz ve sonuncusu İzlanda'da 2010 senesinde bir yanardağ hareketlenmesi ile gerçekleşen volkanik kül bulutu vakasıdır. Araştırmada iflas tahmin modellerinden havacilık endüstrisine özgü bir model olan Airscore modeli ele alınmış, THY A.O. mali verileri ile uygulama yapılarak, geri yayılımlı yapay sinir ağları algoritmaları ile gerçekleştirilen tahminler ile birlikte sunulmuştur.

\section{LITERATÜR TARAMASI}

Giderek globalleşen dünyada işletmeler için iç ve dış çevrenin belirsizlik düzeyi yükselmekte ve pazarda yer alan yerel ve uluslararası rakiplerin sayısı da günden güne artmaktadır. Bu durum göz önüne alındığında, işletmelerin finansal açıdan başarısız olma risklerini öngörebilmek, zamanında gerekli önlemleri alabilmek adına önemlidir. Günümüzde işletmelerin finansal risk analizi için kullandıkları modeller büyük ölçüde oran analizine dayalı olarak yapılmaktadır. Havacılık sektörü gibi, en küçük bir olumsuzluktan etkilenebilecek bir sektörde kriz yönetimi uygulaması, özellikle iflas riski açısından önem taşımaktadır (Göçen vd., 2011).

İşletmenin nakit akışlarının düşmesi, borç yükümlülüklerine bağlı olarak işletmeyi finansal sıkıntıya sokacaktır. Dolayısıyla firmanın nakit akışlarını olumsuz etkileyen her türlü olay, iflas riskini arttırmaktadır. Ekonomideki krizler; müşteriler, çalışanlar, tedarikçiler ve iş ortakları gibi işletmenin çevresindeki ilgilileri olumsuz yönde etkileyecektir. Bu durum, en basit yoldan talebin daralması ile işletmenin nakit akışlarını bozma riski taşımaktadır. Bunlarla birlikte, işletme içi yaşanabilecek olumsuz gelişmeler de faaliyetleri aksatacak ve nakit akışları olumsuz etkilenecektir (Uysal, 2010). 
Finansal başarısızlık ve iflas kavramlarını ele alan önceki yapılan çalışmalarda çoğunlukla araştırmacıların finansal başarısızlığı, iflasa başvurmuş olma biçiminde tanımladıkları görülmektedir. Fakat iflas durumunun yanında yükümlülüklerin karşılanamaması, borç ve veya faizlerinin ödenememesi gibi olaylar da artık işletmenin finansal başarısızlık yaşadığını gösteren durumlar olarak kabul edilmektedir (Özdemir, vd., 2012).

Beaver (1966) ve Altman (1968) isimleri finansal başarısızlık ve iflaslara yönelik çalışmalarda yapılan araştırmalarda öne çıkmaktadır. Altman finansal başarısızlık tanımı olarak "iflas", Beaver ise "başarısızlık" terimini kullanmaktadır (Aktaş, 1997). Yöntem olarak finansal başarısızlığı ölçebilmek için Beaver tek boyutlu, Altman ise çok boyutlu tahmin modellerini kullanan modeller üzerinde durmuştur. Araştırmacılar yaptıkları çalışmalarında muhasebe verilerini kullanmışlar ve oran analizlerinden yararlanmışlardır (Atan ve Güneş, 2004).

Gudmundsson yaptığı araştırmalarda finansal veriler ile beraber finansal olmayan verileri de kullanarak istatistiksel olarak önem testleri yapmış, işletmelerin başarısında girdilerin, politik etkiler ve ekonomik faktörlerin etkisini ele almıştır (Gudmundsson, 1999). Çalışmalarında dikkat çeken noktalardan biri, finansal göstergelerin yanı sıra, karma ve finansal olmayan göstergelerin de performans tahminini yapmada kullanılmalarının faydalı olacağıdir (Gudmundsson, 2002).

Liedtka araştırmasında bu alanda yapılmış olan önceki çalışmalardan yararlanarak havayolu işletmelerinde kullanılan finansal ve finansal olmayan performans göstergelerini sınıflandırmıştır. Finansman göstergelerde yatırım karlılığı, finansal kaldıraç, likidite oranı, nakit durumu, sermaye devir hızı, alacak devir hızı, nakit akışı bulunmaktadır. Finansal olmayan göstergeler hizmet kalitesi, yolcu emniyeti, müşteri memnuniyeti, işgücü verimliliği, uçak verimliliği, yakıt verimliliği, yolcu sayısı başlıkları altında ele alınmıştır (Liedtka, 2002).

Francis vd.'nin yaptığı araştırmada, havayolu işletmeleri tarafından en çok kullanılan finansal ve finansal olmayan göstergeler sınıflandırılmıştır. Finansal olmayan göstergeler operasyonel göstergeler, hizmet kalite göstergeleri, çevresel performans göstergeleri olarak üçe ayrılarak ele alınmıştır. (Francis vd., 2005).

Stepanyan, Amerika Birleşik Devletlerinde yaptığı çalışmasında, ülkede faaliyet gösteren havayollarını likidite, karlılık ve mali yeterlilik açısından incelemiş ve araştırmasında kısa dönem likidite analizi, karlılık analizi ve uzun dönemli mali yeterlilik analizi başlığı altında verdiği oranlar ve verileri kullanmıştır (Stepanyan, 2014).

Tunahan vd. tarafından gerçekleştirilen bir başka çalışmada, bulanık mantık yönemi ile analiz yapılmıştır. Araştırmacılar bulanık mantık yönteminin kullanılmalarının nedenini, belirsizlik içeren değişkenlerin modellenmesinde gösterdiği yüksek performans olarak açıklamışlardır. Çalışmalarında beş farklı finansal oran ile havayolu şirketlerinin finansal risk düzeyleri ölçülmüştür. Havayolu işletmelerinin finansal oranları analizlerde girdi 
olarak kullanılmış, finansal risk düzeyleri ise çıktı olarak elde edilmiştir. Analizlerde kullanılan oranlar iki gruba ayrılarak iki farklı model ile analizler yapılmıştır. Böylelikle analiz sonuçlarının birbiriyle uyumu da göz önüne alınmıştır (Tunahan vd., 2016).

Daha önce bu alanda yapılmış çalışmalar irdelendiğinde, şirket başarısızlıklarının analiz edilmesine yönelik, tek değişkenli modeller ile başlayan çalışmaların ardından doğrusal ayırma analizi, olasılık temelli yaklaşımlar ve yapay zekâ temelli yaklaşımlar olmak üzere farklı yöntemlerin kullanılmış olduğu görülmektedir (Baş, 2015). Ancak literatür araştırmasından da görüleceği gibi, finansal performans ve risk belirleme için kullanılması gereken ölçüt, parametre ve anahtar başarı göstergelerini belirlemede varılmış bir görüş birliği bulunmamaktadır.

Gritta vd.'ye göre, finansal risk değerlendirme ve iflas durumunu tahmin etme modelleri olarak havayolu işletmelerinin temelde kullanabileceği 8 tanesi şu şekilde sınıflandırılmaktadır (Gritta vd., 2008):

- $\quad$ Altman Model(Z-score)

- Altman Zeta Model

- $\quad$ Airscore Model

- Pilarski Model(P-score)

- Gudmunsson Model

- Yapay Zekâ Modelleri:

$\S$ Yapay sinir ağları $(\mathrm{Nn})$

$\S$ Genetik Algoritmalar(Ga)

$\S$ Bulanık Mantık Modeli

\section{HAVAYOLU TAŞIMACILIĞI SEKTÖRÜ GELIŞiMI}

II. Dünya Savaşı’ndan sonra askeri havacılıktan ayrılan sivil havacılık taşımacıllğı sektörü, yaşanan teknolojik gelişmeler ile birlikte son derece hızlı büyüyen sektörlerden biri haline gelmiştir. Hava taşımacıllğı; insanların, kargonun ve postanın yer ve zaman faydası sağlayacak şekilde, bir hava aracı vasıtası ile havadan yer değiştirmesini sağlayan hizmet olarak tanımlanabilmektedir (Gerede, 2002). Havayolu taşımacılığı ile ulusal ve uluslararası ekonomik, teknik, finansal ve kurumsal konularda işbirlikleri gerçekleștirilmekte, insanların, postaların ve malların güvenli, konforlu bir şekilde hızlıca bir yerden başka bir yere taşınması sağlanmaktadır (Dilek, 2007).

Kapsamları açısından iki grupta ele alınan hava taşımacılığı faaliyetleri, genel havacılık taşımacıllı̆̆ ve havayolu taşımacılığı olmak üzere iki farklı alanda gerçekleştirilmektedir. Bu taşımacılık türleri arasında, özellikle kullanılan girdilerin ve süreçlerin özellikleri açısından 
örneğin kar amacı güdülmesi, kullanılan hava araçları, işlev, ölçek, kamuya açıklık gibi konularda önemli farklar bulunmaktadır (Gerede, 2006). Bu çalışma kapsamındaki konular havayolu taşımacilığı çerçevesinde ele alınmıştır.

Havacılık sektörünün gelişimi çeşitli araştırmacılar tarafından farklı şekillerde ele alınarak sınıflandırılmaktadır. Örneğin, hava ulaştırma sektörü Gelişme (1918-1938), Büyüme (19381958), Olgunluk (1958-1978) Liberalleşme (1978-...) sonrası dönemler olarak adlandırılan dört dönemde incelenmektedir. Gelişme döneminde askeri alanda sanayileşen, yıllar içerisinde ise sivil hava taşımacılığına yönelik uçakların üretimiyle ilk yolcu taşımacılığına başlandığı görülmektedir. Büyüme döneminde uzun menzilli tarifeli hava taşımacılığına başlanmıştır. 1958'de başlayan olgunluk döneminde havaalanları ve uçaklardaki teknolojik ilerlemeler sayesinde yolcu sayısı büyük oranda artış göstermiş, havayolu taşımacılığı hızlı ve güvenli ulaşım yolu haline gelmiştir. Liberalleşme döneminde Amerikan hükümeti tam rekabete izin vermiştir. Bu gelişmeleri izleyen Avrupada 1980'lerin sonunda başlayan serbestleşme süreci 1993'te tamamlanmıştır (Wensveen, 2007).

Bu gelişmelere paralel olarak ülkemizde de sivil havacılık sektörü 1925 yllından sonra hızlı bir gelişim göstermiştir.1958 ile 1983 yılları arasında tüm hatlarda Türkiye’nin bayrak taşıyıcısı havayolu olan Türk Hava Yolları Anonim Ortaklı̆̆ı hizmet verirken, özel hava yolu işletmelerinin kurulmasına izin veren kanun ile birlikte hava yolu taşımacıllğı yapan işletme sayısı zamanla artmış ve sektör 1980'lerin ikinci yarısından itibaren hızlı bir gelişim göstermiştir. Özelleştirme amaçları ülkeden ülkeye farklılık gösterse de özelleştirme; verimlilik ve hizmet kalitesini yükseltmeye ve hükümetlerin sağladığı sübvansiyonlarını azaltmaya yönelik olarak yapılmıştır (DPT, 2001).

Türk havacılık sektöründeki son yıllarda görülen ivmelenme, Türk firmaların dış hat payları toplamına da yansımıştır. Yurt dışı havacılık taşımacılığında 2007 yılında oranı yarı yarıya olan yerli ve yabancı hava yolları payı, 2011 yılında yerli hava yolu taşıyıcılarımızın lehine artarak yüzde 56 - yüzde 44 olarak gerçekleşmiştir. Sektördeki istihdamda büyüme sağlanmış, 2003 yılında 65.000 civarında olan personel sayısı, 2013 yılı sonunda 180.000 rakamını aşmıştır. Sektörün cirosu da bunlara paralel olarak 10 kattan fazla artmıştır. Türkiye Cumhuriyeti, taşınan ton/ $\mathrm{km}$ ölçeğinde 2003 senesinde dünya sıralamasına göre 30. sırada yer alır iken, 2013 senesinde dünya genelinde 15. sıraya, Avrupa'da ise 5. sıraya yükselmiştir (Ulaştırma ve Altyapı Bakanlığı, 2017).

Havacılıkta büyüme sürerken finans fonksiyonu açısından yapılan çalışmalar; gelir yönetimi yaklaşımı, birim koltuk kilometre üzerinden satış ve maliyet analizleri, maliyetlerdeki çeşitlilik ve artışlar, makro ekonomik düzeydeki parametrelerin faaliyetlere ve finansal yapıya yansıması vb. şeklindedir. Sektöre özel yapılan çeşitli çalışmalarda araştırmacılar üç temel faktör yani kaynaklar, üretilen çıktı ve hizmetin tüketimine odaklanılan modeller geliştirmeye çalışmışlardır. Fakat bu modellerden yararlanarak işletmelerin finansal performansı 
ve ulaştırma hizmeti arasında ilişki kurulması oldukça zorlaşmaktadır. İşgücü, filo, yer hizmetleri için kullanılan varlıklar ve sermaye gibi girdiler karşısında yapılan uçuş ve yolcu sayısı elde edilen çıktılar arasındaki ilişkinin iyi anlaşılması performansın doğru değerlendirilmesine katkı sağlayacaktır. Doğrudan havayolu endüstrisine ilişkin oranların eksikliği bu sektörde faaliyet gösteren işletmelerin eksiksiz bir biçimde değerlendirilmesi olanağını da s1nırlandırmaktadır (Akkaya, 2004).

Havacilıkta en büyük maliyet kalemlerinden biri olan personel giderlerinin yanına zamanla yakıt maliyetleri de eklenmiştir. Tarihsel olarak faaliyet kaldıraçlarının yüksekliği nedeniyle, havayolu şirketlerinin finansal sonuçları, maliyet ve gelirlerindeki küçük değişikliklere karşı yüksek derecede duyarlı olmaktadır (Lee ve Jang, 2007). Özellikle 21. yüzyılda yaşanan küresel ve/veya ulusal çapta olayların havayollarının finansal durumlarını etkilediği, hatta birçoğunu iflasa sürüklediği görülmektedir. Karlılık ve mali yapıdaki bozulmalar, birçok havayolu işletmesinde risk yönetiminin önemini ortaya çıkartmıştır (Karaer, 2015).

\section{YAPAY SINIIR AĞLARI ÍLE İFLAS RISKI ARAŞTIRMASI}

Büyük Buhran ve II. Dünya Savaşından sonraki dönemde geliştirilen finansal risk değerlendirme modellerine, 90 'lı yıllarda yapay zeka yöntemi ile analizler eklenmiştir. Tahmin gücünün geleneksel istatistik temelli yöntemlere göre daha iyi olması sebebi ile özellikle veri madenciliğine ilişkin problemlerde yapay zeka yaygın olarak kullanılmaktadır (Sevim vd., 2014).

Yapay sinir ağlarında mimari olarak girdi katmanı, ara katman ve çıktı katmanı bulunmaktadır. Yapay sinir ağlarını klasik metotlardan ayıran nokta, değişkenler arasındaki ilişkilerin tanımlama ihtiyacı bulunmadan, kullanıcının sadece girdi/çıktıları belirlemesi ve sistemin kendi içerisinde, önceki veriler yardımı ile kendi kendini eğitip öğrenmesidir (Tan ve Dihardjo, 2001).

\section{IV.1. Araştırmanın Amacı}

Havacılık sektöründe hizmet veren havacılık işletmeleri için sadece gelir ve maliyet sonuçlarını raporlamak ve takip etmek, işletmenin finansal performansını göstermek adına yeterli olmamaktadır. Firmaların şimdiki ve gelecekteki finansal performansını gösteren performans göstergelerine ve bunların sıkı izlenmesine de gerek duyulmaktadır (Wald vd., 2010). Denizcilik işletmelerine benzer şekilde havayolu işletmelerindeki finansal yöneticiler de endüstrinin karşı karşıya olduğu risklere karşı finansal bilgilerini geliştirmek ve devamlı güncellemekle yükümlüdür. Yerel ve uluslararası rekabetle başa çıkabilmek adına teorik finans bilgileri ile birlikte bu alandaki güncel gelişme ve yöntemlerin takip edilmesi önem taşımaktadır (Cerit vd., 2013).

Araştırmada iflas tahmin modellerinden havayollarına özgü bir model olan Airscore ele alınmış, Türk Hava Yolları (THY) A.O. finansal ve operasyonel verileri kullanılarak 
hesaplamalar yapılarak havacılık sektöründe hizmet veren yönetici ve ilgililerin konu hakkında bilinçlenmesi hedeflenmiştir. Havacılık endüstrisini küresel çapta etkileyen 4 olayın yani 11 Eylül 2001 saldırısının, 2003 yılındaki SARS salgınının, 2008 finansal krizinin ve 2010 yılında yaşanan volkanik kül patlamasının THY A.O. üzerindeki iflas riskini, iflas tahmin modellerini kullanarak ortaya koyma ve tahminleme amacını taşımaktadır.

\section{IV.2. Araştırmanın Yöntemi}

Havacılık sektörüne özgü yapılan çalışmalarda ortaya konan ilk modellerden birisi Airscore'dur. Airscore değeri, havacıllk işletmelerinin iflasa ne derecede yakın olduğunu ifade etmektedir. Airscore modeli havayollarının önemli finansal oranlarını ve operasyonel verilerini alarak yaptığı hesaplamalar ile, iflas riski açısından ne kadar güvende olunduğunu ve kısa sürede şirketleri finansal açıdan herhangi bir sorunun bekleyip beklemediğini göstermeyi amaçlamaktadır.

Modeli geliştirirken araştırmacılar, Amerikan havacılık endüstrisinin çoğunluğunu temsil eden büyük, bölgesel ve uluslararası taşımacilık yapan 76 adet işletmenin finansal ve operasyonel verilerini kullanılmışlardır. 76 havayolunun 26 tanesi 1979-1986 yılları arasında mali başarısızlık yaşamıştır. Bu başarısızlıklar Amerika Birleşik Devletleri iflas kanunlarına göre Chapter 10 ve Chapter 11'e girenler, başka bir işletme ile birleşen veya satın alınanlar ile çeşitli mali sebepler ve sıkıntılar yüzünden operasyonlarını tamamen durduranlar şeklinde sınıflandırılmıștır. Modelin doğruluk payı \%76 ile \%83 arasında olup formülü aşağıda verilmiştir (Gritta vd., 2008).

$$
\begin{aligned}
& \text { AIRSCORE }=-0.34140 \mathrm{~T} 1+0.00003 \mathrm{~T} 2+0.36134 \mathrm{~T} 3 \\
& \mathrm{~T} 1=\text { Faiz } / \text { Toplam yükümlülükler } \\
& \mathrm{T} 2=\text { Mil başına faaliyet geliri } \\
& \mathrm{T} 3 \text { = Özkaynaklar / Toplam yükümlülükler }
\end{aligned}
$$

Airscore modelde T1 değişkeni, toplam yükümlülükler için ödenecek olan faiz yükünü yansıtır. T2 değişkeni hava mili başına gelir durumu hakkında bilgi verir. T3 değişkeni firma değeri ve borçlar konusunda ilişkiyi gösterir. Değerin 0,03'den büyük olması sağlık, - 0,095 ten küçük olması sıkıntı işaretidir (Clarke v.d, 2004). Çalışmada Türk Hava Yolları A.O için 2002-2016 senelerine ait geçmiş dönemler için hesaplanan Airscore değerlerinin ileriki çeyrek dönemler için yapay zeka algoritmaları yardımı ile tahmin edilmesi ve elde edilen bulguların yorumu yapılmıştır. Geçmiş dönemlere ait Airscore verileri kullanılarak ileriye yönelik tahminler Matlab 2013a programı vasıtasıyla yapay zeka yöntemi kullanılarak yapılmıştır. Matlab 2013a programı ile veriler eğitim test ve sınama test gruplarına ayrılıp oluşturulan ağ eğitilmiş ve bir sonraki dönemlerin skor değerleri tahmin edilmeye çalışılmıştır. 


\section{IV.3. Araştırmanın Bulguları}

Öncelikle yapay zekâ analizinde kullanılmak üzere geçmiş dönemler için Airscore değerleri hesaplanmıştır. Tablo 1'de verilen THY A.O. için hesaplanan Airscore değerleri incelenen tüm dönemler için sağlıklı olarak adlandırılan alanda yer almıştır. Airscore için yapılan yapay sinir ağları analizinde kullanabilmek için geçmiş senelere ait veriler, çeyrek dönemlik olacak şekilde hesaplanmış (sene başına 4 tane) ve öncelikle bütün değişkenler normalize edilmiştir. Eğitim seti olarak verilerin 3'te 2'si kullanılmış, test ve sınama seti olarak verilerin 6'da 1'i seçilmiştir. Gizli katman sayısı, girdi sayısının karesi alınarak hesaplanmıştır. Ağ eğitimi için Levenberg-Marquardt geriye yayılma algoritması, yapay sinir ağlarının eğitiminde sağlamış olduğu hız ve kararlılık nedeni ile tercih edilmiştir (Wilamowski, Chen, 1999). Uygulamada aktivasyon fonksiyonu olarak "logsig" fonksiyonu ve eğitim algoritması olarak "trainlm" kullanılmıştır.

Tablo 1. Airscore - THY A.O 2002-2016 Dönemi Sonuçları

\begin{tabular}{|l|c|c|c|c|c|c|c|c|c|c|c|c|c|c|c|}
\hline $\begin{array}{l}\text { Değişken/ } \\
\text { Yll }\end{array}$ & $\mathbf{2 0 0 2}$ & $\mathbf{2 0 0 3}$ & $\mathbf{2 0 0 4}$ & $\mathbf{2 0 0 5}$ & $\mathbf{2 0 0 6}$ & $\mathbf{2 0 0 7}$ & $\mathbf{2 0 0 8}$ & $\mathbf{2 0 0 9}$ & $\mathbf{2 0 1 0}$ & $\mathbf{2 0 1 1}$ & $\mathbf{2 0 1 2}$ & $\mathbf{2 0 1 3}$ & $\mathbf{2 0 1 4}$ & $\mathbf{2 0 1 5}$ & $\mathbf{2 0 1 6}$ \\
\hline T1 & 0,015 & 0,182 & 0,062 & 0,026 & 0,028 & 0,030 & 0,146 & 0,034 & 0,022 & 0,020 & 0,031 & 0,031 & 0,017 & 0,016 & 0,015 \\
\hline T2 & 5,141 & 3,365 & 1,199 & 1,594 & 1,523 & 2,777 & 8,015 & 3,803 & 1,642 & 0,560 & 4,777 & 2,249 & 4,597 & 7,280 & 0,004 \\
\hline T3 & 0,231 & 0,427 & 0,604 & 0,551 & 0,538 & 0,631 & 0,611 & 0,672 & 0,543 & 0,378 & 0,404 & 0,378 & 0,403 & 0,420 & 0,379 \\
\hline Airscore & $\mathbf{0 , 0 7 9}$ & $\mathbf{0 , 0 9 2}$ & $\mathbf{0 , 1 9 7}$ & $\mathbf{0 , 1 9 0}$ & $\mathbf{0 , 1 8 5}$ & $\mathbf{0 , 2 1 8}$ & $\mathbf{0 , 1 7 1}$ & $\mathbf{0 , 2 3 1}$ & $\mathbf{0 , 1 8 9}$ & $\mathbf{0 , 1 3 0}$ & $\mathbf{0 , 1 3 6}$ & $\mathbf{0 , 1 2 6}$ & $\mathbf{0 , 1 4 0}$ & $\mathbf{0 , 1 4 7}$ & $\mathbf{0 , 1 3 2}$ \\
\hline
\end{tabular}

Modelin performans ölçümü için hata kareleri ortalaması (MSE) değerlerine bakılmış, denemelerde en küçük hata kareleri ortalamalarını veren değerler işleme alınmıştır. Yapılan analizlerde, performans verileri stabil olana kadar ağın eğitimine devam edilmiştir. Airscore’u oluşturan değişkenlerde, 4 zaman gecikmesi için bulunan en küçük hata karelerinin ortalaması sonuçları incelenmiş, ilk değişken için zaman gecikmesi 1, ikinci değişken için zaman gecikmesi 2, son değişken için zaman gecikmesi 2 olarak en iyi sonuçları verdiğinden bu değerler alınarak gerekli hesaplamalar yapılmıştır.

$\mathrm{Bu}$ aşamalardan sonraki adımda simülasyon algoritması geliştirilerek, her değişken için 0 ile 1 aralığında normalizasyon yapılmasının ardından, eğitilmiş ağ değerleri veri olarak verip tahminleme yapıldıktan sonra normaliazsyon geri alınarak gerçek tahmin değeri bulunmuştur. Veriler normalizasyon işlemi yapılarak, boyutsuz hale getirilmiş olmaktadır (Emrah vd., 2007).

Yapılan analizler sonucu THY A.O'ya ait 2002 ile 2019 yılları arasını kapsayan Airscore modeli gerçek ve yapay sinir ağları tahmin değerleri elde edilerek, ilgili grafik ve verileri aşağıda verilmiştir. Bu yıllardan ileriye yönelik olarak değerleri tahminlenen 2017, 2018 ve 2019 yılları için bulunan değerler 0,03’ten büyük çıktığı için THY A.O’nun iflas tahminleri, Airscore’a göre sağlıklı olarak nitelendirilen alanda yer almışlardır. Özet olarak belirtmek gerekirse, 2017-2019 
yıllarında THY A.O işletmesi için Airscore modeli tahminlerine göre, herhangi bir iflas riski bulgusuna rastlanmamıştır.

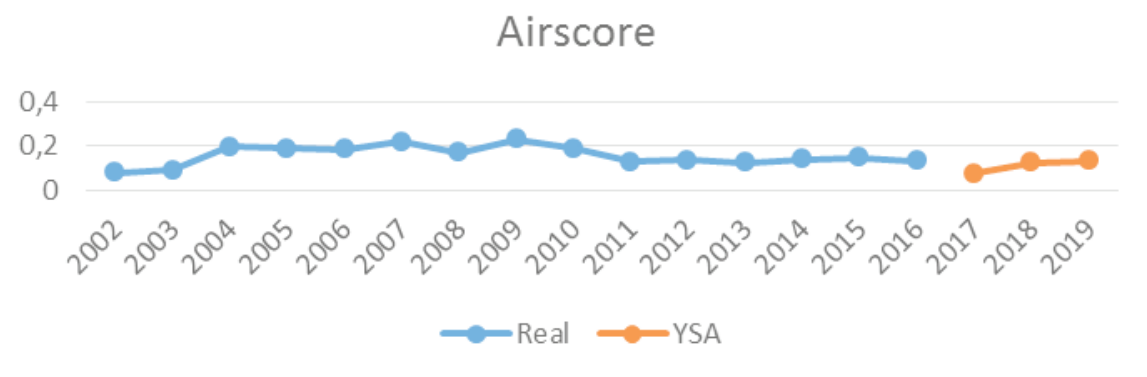

Şekil 1. THY A.O Airscore Gerçek ve Tahmin Değerleri

Grafik 1'de görüldüğü üzere tahminlenen üç senelik dönem için bulunan Aircose modeli değerleri, sağlıklı olarak nitelendirilen alanda yer almaktadırlar.

\section{SONUÇ ve ÖNERILER}

Havayolları ekonomik açıdan özellikle ticaret ve turizm için önemli kurumlar olduklarından ve geçmiş yıllarda dünyada ve ülkemizde çeşitli havayollarının finansal başarısızlığa ve iflasa düştükleri görüldüğünden, finansal sağllğın yakından takibi ve takip konusunda yapılan uygulamalar önem arz etmektedir. Çalışmada bu bağlamda havayollarına özel olarak geliştirilmiş bir model olan Airscore ele alınmıştır. Airscore modeli sonuçlarına göre Türk Hava Yolları A.O’nun yıllık verilerine bakıldığında hesaplanan tüm değerler $0,03^{`}$ ten büyük olduğundan iflas riski açısından işletmenin sağlıklı alanda olduğu görülmüştür. Airscore incelemesinin yanı sıra yapay sinir ağları kullanılarak ileriki dönemleri çin analizler yapılmış, yapılan tahminlere göre 2017, 2018 ve 2019 yılları için 0,03'den büyük rakamlar bulunduğundan işletmenin sağlıklı alanda olacağı bulgularına ulaşılmıştır.

Gayet tabii diğer tüm konularda olduğu gibi bu konuda da daha fazla çalışma yapılmasına ihtiyaç vardır. Daha farklı kaynaklar incelenerek konu ve sonuç zenginleştirilebilir. Analizler özellikle sektör çalışanlarına ve bundan sonraki yapılacak çalışmalara yol göstermek amacı ile yapılmıştır, diğer araştırmacılar farklı gösterge ve rasyolar ekleyerek raporları genişletebilir, formatları ihtiyaçları doğrultusunda geliştirebilirler.

\section{Yararlanılan Kaynaklar}

Akkaya G.C. (2004). Finansal Rasyolar Yardımıyla Havayolları İşletmelerinin Performansının Değerlendirilmesi. Dokuz Eylül Üniversitesi İ.I.B.F.Dergisi. 19(1), 15-29. 
Aktaş R. (1997). Mali Başarısızlık (İşletme Riski) Tahmin Modelleri. Türkiye İş Bankası Kültür Yayınları, İstanbul.

Altman E. (2000). Predicting Financial Distress of Companies:Revisiting the Z-Score and Zeta Model. Nyu. New York. 7-36.

Atan, M. ve Güneş, B. (2004). İMKB’ye Kote Şirketlerde Bilançoya Dayalı Risk Analizi Ve Erken Uyarı Göstergelerinin Araştırılması, Dokuz Eylül Üniversitesi 4. İstatistik Günleri Sempozyumu. İzmir.

Beaver W. H. (1966). Financial Ratios As Predictors Of Failure. Journal of Accounting Research. 71-111.

Bredart, X. (2014). “Bankruptcy Prediction Model Using Neural Networks”, Accounting and Financial Research. 3(2), 124-128.

Cerit G., Deveci A. ve Esmer S. (2013). Denizcilik Işsletmeleri Yönetimi. Beta Yayınları. 1.Basım, İstanbul.

Clarke J., Lee A. ve Miller B. (2004). Is Air Transportation Financially Sustainable. MIT International Center for Air Transportation.

Dilek Ö. (2007). Şehirlerarası Havayolu Talep Tahmini: Erzurum Üzerine Bir Uygulama, Atatürk Üniversitesi Sosyal Bilimler Enstitüsü. İktisat Anabilim Dalı Yüksek Lisans Tezi, Erzurum.

DPT - Devlet Planlama Teşkilatı (2001). Sekizinci Beş Yıllık Kalkınma Planı, 2001-2005: Ulaştırma Özel İhtisas Komisyonu Raporu Hava yolu Ulaştırma Alt Komisyon Raporu. DPT:2584, ÖİK:596, Ankara.

Dursun D.G. ve Birdal İ. (2011). Krizlerin Tahmin Edilebilirliği: 2008 Krizi Örneği. Yönetim: İstanbul Üniversitesi İşletme İktisadı Enstitüsü Dergisi. 70, 22.

Emrah D., Işık S. ve Sandalcı M. (2007). Günlük Buharlaşmanın Yapay Sinir Ağları Kullanarak Tahmin Edilmesi. İMO Teknik Dergi. 4119 - 4131.

Francis G., Humphreys I. ve Fry J. (2005). The Nature And Prevalence Of The Use Of Performance Measurement Techniques By Airlines. Journal of Air Transport Management. 11 (4), 207 217.

Gerede E. (2002). Havayolu Taşımacılığında Küreselleşme Ve Havayolu İşbirlikleri-THY AO.da Bir Uygulama. Anadolu Üniversitesi Sosyal Bilimler Enstitüsü (Yayımlanmamış Doktora Tezi). Eskişehir.

Gerede E. (2006). Sivil Havacılık Faaliyetlerin Sınıflandırılması Ve Türkiye’de Hava Taşımacılı̆̆ı Faaliyetlerinin Tanımlanmasına İlişkin Sorunlar. HaSeM'06 Kayseri VI. Havacılık Sempozyumu. Nevşehir, 197-203.

Göçen S., Yirik Ş. ve Yilmaz Y. (2011). Türkiye’de Krizler Ve Krizlerin Turizm Sektörüne Etkileri. Süleyman Demirel Üniversitesi İİBF Dergisi. 16(2), 493-509. 
Gritta R.D., Adrangi B., Davalos S. ve Bright D. (2008). A Review of the History of Air Carrier Bankruptcy Forecasting and the Application of Various Models to the US Airline Industry: 1980-2005. Södertörn Academic Studies. 193-214.

Gudmundsson S. (1999) Airline Failure And Distress Prediction: A Comparison Of Quantitative And Qualitative Models. Transportation Research. Part E 35, 155-182.

Gudmundsson, S. (2002). Airline Distress Prediction Using Non-Financial Indicators”, Journal of Air Transportation. 7(2), 3-23.

Karaer B. (2015). Havayolu İşletmeciliğinde Yakıt Maliyetleri Ve Yönetimi. Gazi Üniversitesi Sosyal Bilimler Enstitüsü. İșletme Anabilim Dalı İșletme Bilim Dalı Doktora Tezi, Ankara.

Lee, J.-S. ve Jang, S. (2007). The Systematic-risk Determinants Of The US Airline Industry. Tourism Management 28(2), 434-442.

Liedtka S. L. (2002). The İnformation Content Of Nonfinancial Performance Measures İn The Airline Industry, Journal of Business Finance and Accounting. 29(7) - (8), 306-686.

Özdemir F.S., Choi Frederick D.S. ve Beyazıtlı E. (2012). Finansal Başarısızlık Tahminleri Yönüyle Ufrs Ve Bilginin İhtiyaca Uygunluğu. İsmmmo Mali Çözüm Dergisi. İstanbul.

Sevim, C., Öztekin, A., Bali, O., Gümüş, S. ve Güresen, E., (2014). Developing An Early Warning System To Predict Currency Crises. European Journal of Operational Researh. 237, 10951104.

Stepanyan A. (2014). Traditional Ratio Analysis in the Airline Business: A Case Study of Leading U.S Carriers. International Journal of Advances in Management and Economics. 3(2), 175189.

Tan, C. N. W. ve Dihardjo, H. , (2001). A study On Using Artificial Neural Networks To Develop An Early Warning Predictor For Credit Union Financial Distress With Comparison To The Probit Model. Managerial Finance. 27, 56-77.

Tunahan H., Esen S. ve Takıl D. (2016). Havayolu Şirketlerinin Finansal Risk Düzeylerinin Bulanık Mantık Yöntemi İle Karşılaştırmalı Analizi. Journal of Accounting, Finance and Auditing Studies. 2(2), 239-264.

Ulaştırma ve Altyapı Bakanlığı. (2017). Ulaşan ve Erişen Türkiye 2017: Havacılık ve Uzay Teknolojileri. http://www.udhb.gov.tr/images/faaliyet/a5ec26a31a72281.pdf (Erişim tarihi: 01.03.2018).

Uysal B. (2010). Sermaye Yapısını Belirleyen Faktörler:Sektörel Bir İnceleme. T.C Ankara Üniversitesi Sosyal Bilimler Enstitüsü. İşletme Anabilim Dalı Yüksek Lisans Tezi. Ankara.

Wald A. Ve Fay Christoph, G.R. (2010). Introduction to Aviation Management, LIT Yayınclik. Münster.

Wensveen, J. G. (2007). Air Transportation: A Management Perspective. Aldershot: Ashgate.

Wilamowski ve B.M., Chen, Y. (1999). Efficient Algorithm For Training Neural Networks With One Hidden Layer. International Joint Conference on Neural Networks. 3, 1725-1728. 


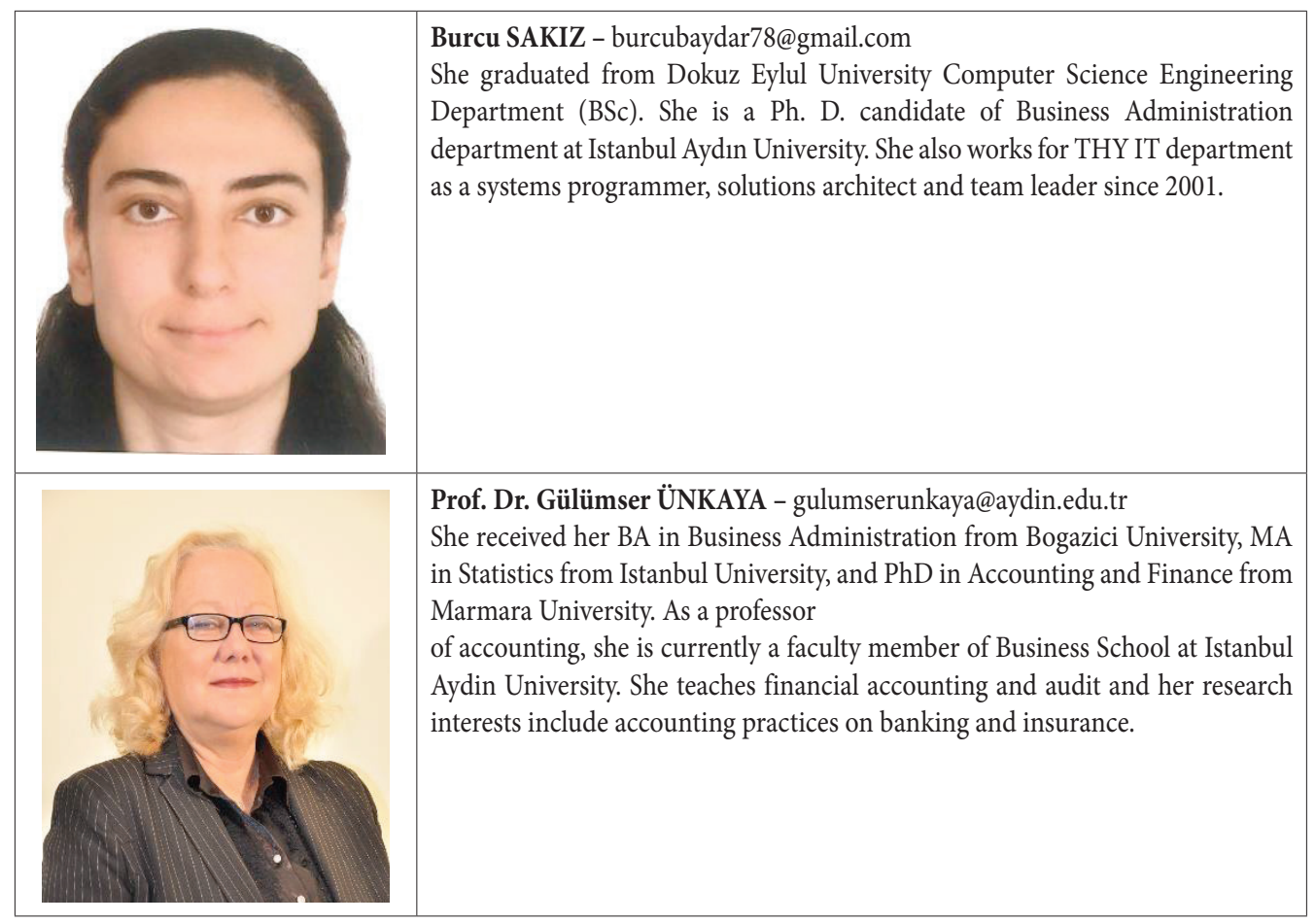

